\title{
Predictors of Dropout from Outpatient Mental Health Services
}

Sir,

We thank the reader for a critical reading and expressing valid concerns related with the methodology. The first concern raised is about the limited sample size, which is a genuine one and has already been considered as a shortcoming. ${ }^{[1]}$ It must be remembered that the given study was not funded and the authors had limited resources at their disposal. Hence, it was decided to include every tenth patient who attended the hospital. A mindful compromise between the resources available 
and the research question that needs to be answered was done.

The second concern is regarding the arbitrary classification among illiterates. We recorded gradients of education level, and when we ran statistical models, we found that people who received no formal education were less likely to dropout from the treatment at 6 months than people who received any formal education, as has been reported in the study. For the sake of brevity, we categorized the data into statistically meaningful categories.

Further, more research is needed to replicate and find reasons for this counter-intuitive result. We have made two speculations that are open to hypothesis-based testing. The author of the letter, we presume, is also only making hypothesis about inability to afford cost of treatment, indicating poor socioeconomic status. They will also need to be tested.

\section{Acknowledgment}

The authors would like to thank the State Institute of Mental Health, Institute of Mental Health, Pt BDS University of Health Sciences, Rohtak, Haryana, India, for their cooperation in the study.

\section{Financial support and sponsorship}

Nil.

\section{Conflicts of interest}

There are no conflicts of interest.
Nikhil Jain, Sidharth Arya, Rajiv Gupta

Department of Psychiatry, Institute of Mental Health, Pt BDS University of Health Sciences, Rohtak, Haryana, India

Address for correspondence: Dr. Sidharth Arya, Institute of Mental Health, Pt BDS University of Health Sciences, Rohtak - 124 001, Haryana, India. E-mail: draryasid3188@gmail.com

\section{REFERENCE}

1. Jain N, Arya S, Gupta R. Predictors of dropout from outpatient mental health services; a study from Rohtak, India. J Neurosci Rural Pract 2017;8:535-9.

This is an open access journal, and articles are distributed under the terms of the Creative Commons Attribution-NonCommercial-ShareAlike 4.0 License, which allows others to remix, tweak, and build upon the work non-commercially, as long as appropriate credit is given and the new creations are licensed under the identical terms.

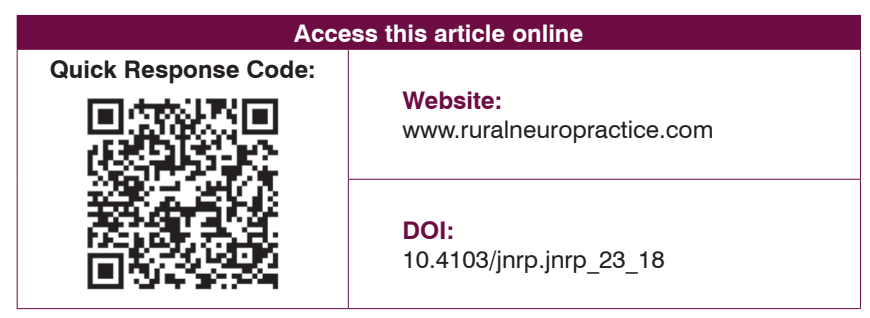

How to cite this article: Jain N, Arya S, Gupta R. Predictors of dropout from outpatient mental health services. J Neurosci Rural Pract 2018;9:440-1. 